This is an electronic reprint of the original article. This reprint may differ from the original in pagination and typographic detail.

Author(s): Gavriushenko, Mariia; Lindberg, Renny S. N.; Khriyenko, Oleksiy

Title: $\quad$ Smart Educational Process Based on Personal Learning Capabilities

Year: $\quad 2017$

Version:

Please cite the original version:

Gavriushenko, M., Lindberg, R. S. N., \& Khriyenko, O. (2017). Smart Educational Process Based on Personal Learning Capabilities. In L. G. Chova, A. L. Martínez, \& I. C. Torres (Eds.), EDULEARN17 Proceedings. 9th International Conference on Education and New Learning Technologies (pp. 6316-6324). IATED Academy. EDULEARN proceedings. https://doi.org/10.21125/edulearn.2017.2434

All material supplied via JYX is protected by copyright and other intellectual property rights, and duplication or sale of all or part of any of the repository collections is not permitted, except that material may be duplicated by you for your research use or educational purposes in electronic or print form. You must obtain permission for any other use. Electronic or print copies may not be offered, whether for sale or otherwise to anyone who is not an authorised user. 


\title{
SMART EDUCATIONAL PROCESS BASED ON PERSONAL LEARNING CAPABILITIES
}

\author{
Gavriushenko Mariia ${ }^{1}$, Lindberg Renny S. N. ${ }^{2}$, Khriyenko Oleksiy ${ }^{1}$ \\ ${ }^{1}$ Faculty of Information Technology, University of Jyväskylä, Jyväskylä (FINLAND) \\ ${ }^{2}$ Department of Software, Ajou University, Suwon (REPUBLIC OF KOREA)
}

\begin{abstract}
Personalized learning is increasingly gaining popularity, especially with the development of information technology and modern educational resources for learning. Each person is individual and has different knowledge background, different kind of memory, different learning speed. Teacher can adapt learning course, learning instructions or learning material according to the majority of learners in class, but that means that learning process is not adapted to the personality of each individual learner. That is why it is important to have smart educational process based on personal learning capabilities. This paper presents a literature survey on different learning systems which detects learning progress and based on that a model of smart educational system which use knowledge engineering and Watson technology is proposed. This system is relevant both for basic education and for adult education.
\end{abstract}

Keywords: Smart educational process, personalisation, Ontology, Watson Technologies.

\section{INTRODUCTION}

Development of information technologies has quickly changed approach to learning and education, with the emergence of more mobile technologies and faster computers. A myriad of methods to deliver these educational innovations has emerged. For instance, with children educational process could be presented in a game format, or more social platform.

Developing e-learning has become more popular due to several benefits tied to it, such as: mobility and possibilities to customize user navigation [1], [2]. Modern methods of learning with the help of computers have tightly entered the educational process, from pre-school education to retraining. Generally the learning topics are presented in logical chain, moving from topic to topic. The process of enhancing the level of learning, in a company for instance, requires paying attention to the personal needs of the employees.

The problem of innovative teaching methods lies in their wide applicability due to the advantages mentioned above, but at the same time there are significant drawback - it is the passage to a new level with a specific threshold. When a person collects certain percentage of correct answers, he or she can proceed to the next level, not taking into account that part of the tasks were not performed or were performed incorrectly. This is an important issue, because most topics are interconnected and "gaps" in the learner's knowledge should be avoided.

Also, an important issue is related to adult learning, when it is not necessary to start learning some topic from the scratch, but when person already has knowledge background in specific field and just needs to improve his knowledge in specific topic related to his background. This is especially significant for those people who need to learn more content and improve their qualification to be more competitive. Unfortunately, not many learning platforms take into account learner's background while suggesting some material for additional learning and because of that learner has to spend more time for searching relevant material.

To solve these issues, we surveyed papers on existing learning systems to see how they deal with learner progress assessment. Based on our findings we designed our education support system. This system aims to make the process of learning more personalized taking into account assimilability of the content and existing knowledge background. Setting the threshold value of $100 \%$ is not a solution, however since the user might also lose interest, if the system is too demanding. Tracking the user's progress and general level of understanding is more important than superfluous obstacles. 


\section{BACKGROUND}

A literature survey on e-learning was conducted to see how different systems detect users learning progress. 36 papers in total were accepted as part of our survey, which discuss: tutoring, learning or e-learning systems. Due to the fast pace of advancement of technological concepts and methods we would only accept papers that were published in 2010 or after. Google Scholar, ACM library and IEEE Xplorer were used to search for the publications.

Our core focus was on the handling of learning process and especially how the systems ensure that users understood the learning topic. Another point of interest was on how the system reacts to any detected learning difficulty. Out of the 36 papers discussing learning systems, 13 had no detection for possible difficulties that the user might be having. The remaining 23 systems approach to learning detection varied somewhat, but could be roughly labelled within two distinct types: By testing and user behaviour analysing.

The systems that used testing were labelled to three sub groups: loop, feedback and other. Systems that use loop commonly had either periodic quiz, or a larger questionnaire at the end of a learning topic and depending on the user's results the system would not proceed further before user learning level was at a satisfactory level. In total we labelled eight systems within the loop sub category. Depending on the user's answers the loop-test systems reacted in slightly varying ways, by either presenting more material [3], [4], [5] or simply show the same materials and not show any new materials before the system is satisfied that the user has reached a satisfactory learning level [6], [7], [8]. With two systems the systems would either return to the topic at later point [9] or only suggest the user to sticking with the current topic, but not enforcing it [10]

Learning systems labelled under the sub group "feedback", essentially these systems also have questionnaires that the user must complete in order to proceed further, but the system will only show results of the questionnaire before moving further. Only one learning system also presented links for additional learning material depending the user's results [11]. Only one learning system used the test results to modify internal features that in turn affect future quizzes [12].

Last sub group was simply labelled as other as they were slightly too varied to be placed under either loop or feedback. In the following Table 1 we show the evaluated learning systems.

The group labelled as "By analysis" simply put, utilize user behaviour and other various methods to try and deduce the level of knowledge by the user. These systems have essentially no testing of the user, however they do have profiles created that two of the systems updated by prompting for the user to give feedback at the end of a cycle [13], [14]

The remaining 13 surveyed systems had no learning level detection with one exception. One system essentially had no internal analysis of the learner's level of knowledge, but instead the system had the users assess and each other[15]

Table 1.List of surveyed papers on learning systems and what type of methods they use to detect user learning.

\begin{tabular}{|c|c|c|c|c|c|c|}
\hline Method & Type & & & Pape & & \\
\hline & & [3] & [6] & [7] & [5] & [9] \\
\hline & loop (8) & [10] & {$[8]$} & [4] & & \\
\hline By test & feedhack (6) & [16] & [17] & [18] & [11] & [19] \\
\hline & teedback (b) & [12] & & & & \\
\hline & other (4) & [20] & [21] & {$[22]$} & [23] & \\
\hline & analysis (4) & [24] & [25] & [13] & [14] & \\
\hline & & [26] & [27] & [28] & [29] & [30] \\
\hline No & etection (14) & [31] & [32] & [33] & [34] & [35] \\
\hline & & [36] & [37] & [38] & [15] & \\
\hline
\end{tabular}

\section{SMART EDUCATIONAL PROCESS}

In this section we argue that there is a need for system which supports smart educational process based on personal learning capabilities. This process is important for both, basic education and adult 
education. Proposed method is taking into account person's knowledge background and rate of material compatibility.

\subsection{Basic education process}

For basic education -preschool, primary, secondary and higher- a person is usually expected at first to learn the education material given and then perform a certain set of tasks. The topics for study are sequential, from simple to more complex ones, which, in turn, can be based on several previous ones.

Unfortunately, majority of schools do not have time to ensure that all students have fully understood the underlying education materials during an ongoing course that form the crucial base for more advanced, but related topics. Thus there is a strong likelihood that students will form knowledge gaps that will only accumulate as the course progresses. At its worst this can lead to a student unable to proceed forward in the course and is thus forced to retake it.

The tasks (assignments) after the study of the material are presented in the form of a straight line. When a student solves several problems in a row correctly (assuming 10 tasks), this indicates that the student has thoroughly understood the topic and can proceed to next topic. If a student makes a mistake somewhere and answers incorrectly from the task cycle, then this test is followed by additional testing and the student cannot proceed to the next topic. An error is an incorrect answer or a long response rate (presumably, this time is spent searching information in external sources). Then, for this topic, and what is related to it, an additional set of tasks is given, which allows learner to fix the material that is not learned well enough. The student is again invited to solve the problem until he answers specific percentage of right answers correctly.

We introduce three amounts, which could be changed:

1) $k$ - fixed amount of tasks;

2) $l=k-\% k-$ means how many mistakes person can make in $k$;

3) $m$ - amount which experts put for correlation of true answers to false answers;

$N_{\text {true }}$ - amount of correct answers;

$N_{\text {false }}$ - amount of incorrect answers.

If this equation is correct, learner can move to the next level:

$$
l \geq \frac{N_{\text {true }} \times \frac{k}{m}}{N_{\text {false }}}
$$

The more mistakes a learner makes - the more time is spent by the learner on solving assignments and reading additional material until next level.

This approach allows for more dynamic learning and also minimizes the forming of any knowledge gaps. This approach also makes it easier for the system to deduct what specific topic the learner might be struggling with and when they are outside their zone of comfortable learning speed.

Each task should have its own weight (complexity). And complexity could be the sum of topics in the tasks (the weight of the tasks should be set by the experts or teachers). The severity of tasks correlates with the speed of the learner. If a person is slow to answer (by an average formed from all learners) this could indicate that one or more previous topics have not been mastered fully.

When a learner is stuck or makes mistakes, it is necessary to give them the proper guidance to help them. And if something is not clear from the explanation, then the person should have the ability to allocate a certain part of the material, which is incomprehensible to him and to receive a further explanation.

If a person quickly and successfully copes with the tasks, then the rate of learning should be optimized for the individual. For an adept learner this can be achieved with fewer assignments that are more complex that utilize several topics at once. It is not difficult for some students to quickly solve problems and move on to more complex topics and tasks that are based on several topics at once. If a person is 
capable of solving tasks without mistakes in a row, then he can be given less tasks on the next level and several subtopics to study and solve:

$$
\text { if }\left\{\begin{array}{l}
N_{\text {true }_{i}}=k_{i}, k_{i+1}=k_{i}-p \\
\left(N_{\text {true }_{i}}>k_{i}\right) \& \&\left(k_{i}<k_{0}\right), k_{i+1}=k_{i}+p \\
\left(N_{\text {true }_{i}}>k_{i}\right) \& \&\left(k_{i} \geq k_{0}\right), k_{i+1}=k_{0}
\end{array}\right.
$$

If there is a combined task - then it is good to have a counter, which will take into account mistakes which the learner is making and where, as well as count which subtopic was answered incorrectly more times than others. After that system should provide additional material for study.

Because the system will have assignments that combine not only the current topics, but likely also additional sub topics the learned might have been struggling with. This can make the presented number of topics somewhat complicated, which necessities modifying the formula to mitigate this:

$$
l \geq \frac{\sum_{i=1}^{N_{\text {true }}} \frac{d_{\text {tasklevel }}}{d_{\text {currentlevel }}}}{\sum_{i=1}^{N_{\text {false }}} \frac{d_{\text {tasklevel }}}{d_{\text {currentlevel }}}}
$$

Tasks can include:

1) The choice of one of the proposed options for answers,

2) Formula or question, where the answer must be written in text form.

In order to analyse this kind of natural language input, there are novel cognitive computing approaches for the design. This means that communication between systems will occur more natural way.

There are several cognitive computing services that could be used for this analysis:

1) IBM Watson [39],

2) Google mind cognitive services like Microsoft Azure [40].

These services allow developing a natural language form.

\subsection{Adult education process}

The speed of constantly emerging new technologies, utilized by consumers and by the companies making these products for the consumers, is only gaining momentum. Because of that employees of large companies need to study constantly additional material, be aware of new products and other things in order to remain competitive and professional in their field.

This field of work as IT is an exponentially developing field of human activity, in which new tools, technology, applications are continuously emerging, thus it can be said that the IT sphere is where "all life learning" rule is applied.

Unlike a student who we assume starts from zero an employee of a technology company is likely to have some level of knowledge of a new topic he or she might be learning, with some knowledge gaps here and there. Our learning system would be able to target those gaps, before moving on the actual topic at hand.

If a person's knowledge is lower in a certain area, then this is a certain gap between the study material and his knowledge, and then knowledge retrieval is necessary, where a person reaches his level and then studies what is necessary. It should be taken into account that people have different knowledge base, so when searching for spaces, each person will have different top down (different depth in the material that needs to be studied). Some people should study the material superficially to sort out a certain topic, and some should go deeper in order to thoroughly understand all the nuances.

Unlike with a student, this form of "adult" education, does not force to the learner to approach the assignments of topics in set order. A person will learn from a case based study. The system will offer a 
practical example to study the material. If the system identifies a gap in the learners knowledge it will offer to present additional study materials in more detail. After the learner gets a detailed explanation, system searches in the database of the total content, provides a link for relevant material. This training is based on the principle of browsing.

\section{SYSTEM'S MODEL PROPOSAL. METHOD AND ARCHITECTURE}

An effective computer-supported learning tool that helps in learning process requires efficient knowledge representation, where it is possible to analyse data and make sense of it using specific rules.

Ontologies, which have proved themselves from ancient times as an approach for the integration of data and knowledge in science, are one of the modern methods allowing obtaining a quick idea of the content of an information resource. Ontologies are used for formal specification of concepts and their relations, which characterize a specific knowledge domain. For this system's model proposal, the advantage of using this approach of knowledge representation is a formal structure, which greatly simplifies the processing [41], [42], [29].

Ontologies have been used in educational domains to build, organize and update learning resources like learners profiles, learning objects, learning paths, academic performance, etc [43]. Ontology will be served as knowledge engineering process which will store and analyse data about learning topics, assignments, learning material and personal information of learners which shows there learning background. Every system which has knowledge engineering process has to have domain experts. These people will compose tasks and comment level of passing those tasks. Tasks could be written with different levels of complexity, which consists of one or several topics. Also, experts will provide information for each topic, also what will be an optimal minimum for checking if person learned topic or not. Each topic will have its own optimal minimum of tasks.

After learning some material learner has to pass specific amount of tasks and he has to solve them with specific threshold according to formulas presented in Section 3.1. The counter will be counting false answers and detecting knowledge gaps checking the relationships between topics in the Ontology.

In the proposed system, it is necessary to conduct an analysis of the learner's behavior. If system sees that a person makes mistakes, then after answers correctly, then again makes mistakes, then in this case it is necessary to conduct an analysis, and, perhaps, there is some pattern that the topics are related to other sub-themes, and in which percentage (some in less, some in more).

If person is doing well and he is fast in learning and in testing process, then on the next stage of testing he will get fewer tasks, but not less than defined minimum, for faster learning. But if person if making mistakes, then system is adding more assignments to solve which will consist also from the previous topics which are the basis for this particular one, and more learning material to study.

If learner makes a mistake in the task, he himself can allocate a specific piece of material that he does not understand. Then the system will offer him an explanation, based on which sub-themes served as the basis of this topic. The system will look how to fill these gaps. The system should be semiautomated and use technologies such as Watson Retrieve and Rank [44]. Retrieve and Rank service will search the most relevant information from a collection of documents. Using this service it is possible to collect and load material, train the machine learning rank model, query service and evaluate results. The person gets a topic to learn, does not understand the paragraph, singles it out and runs the service for more in-depth study of the material. For example, it is possible to find quickly some solutions from technical manual. If a person does not understand the piece of content, then he can dig deeper into the topic, where on the fly to find more relevant one, and dig deeper and deeper until he reaches his level of knowledge base with which he can start without problems to study the material.

Architecture of the proposed system model is presented on Fig.1.It shows main blocks of the smart educational process. Our approach follows very much the style that in the background section was labelled as "test by loop". Periodic testing is the only certain way to ensure that no large knowledge gaps emerge. Relying on just analysis or giving the users only feedback is not enough. We've built on the existing models slightly on how wrong answers affect the process. The user is not locked inside a small loop that concentrates on the topic at hand, rather the system will start pinpointing where the knowledge gap is. Thus the system also, in a manner, does a minor scale retention test for the user. 


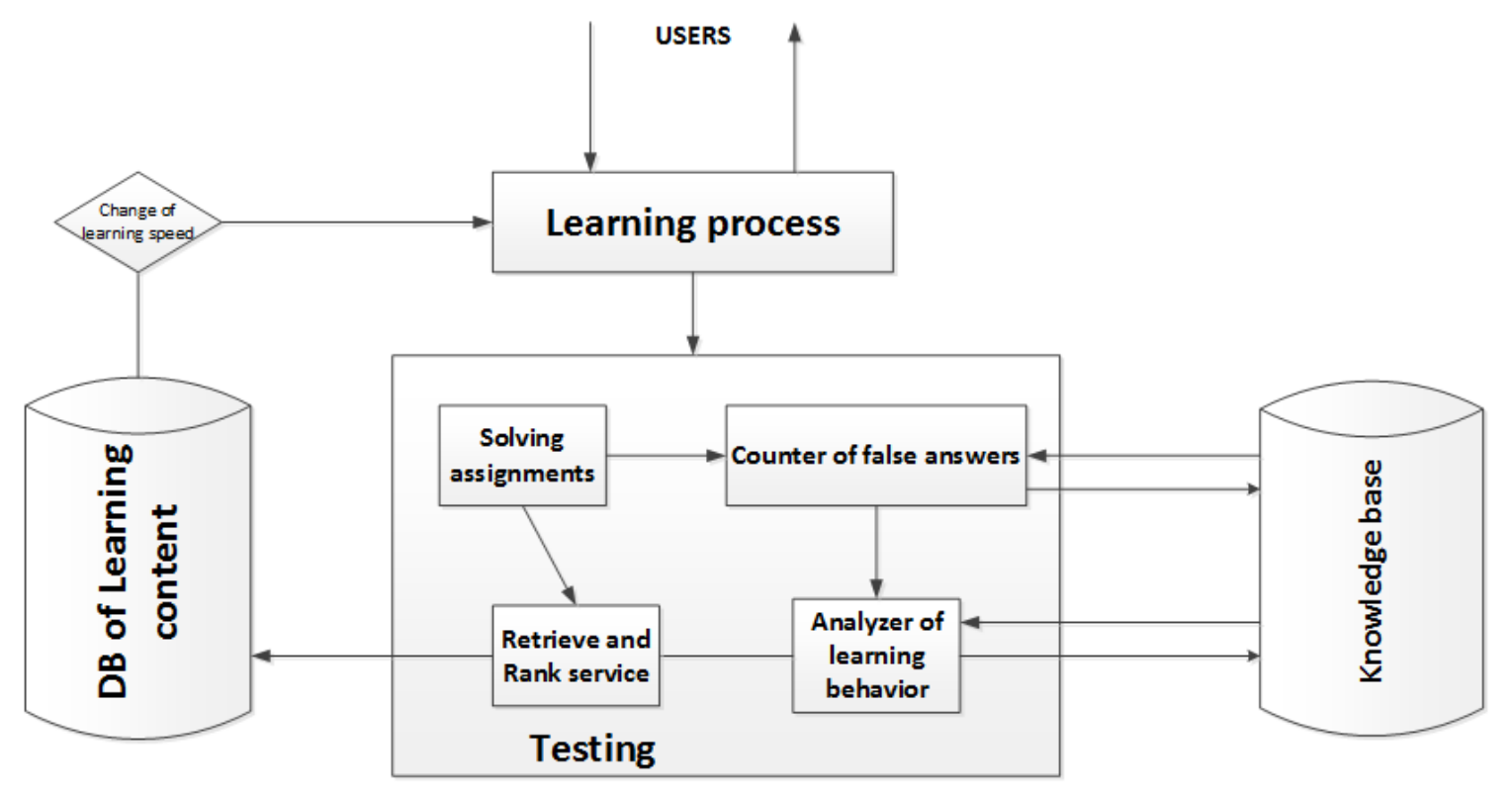

Figure 1. Architecture of smart educational process.

\section{CONCLUSIONS}

This paper propose solution for enhanced personalized learning system, which uses a technology of knowledge gaps reduction. It consists of the fact that at a certain threshold of passing threads, person will have the opportunity to proceed to the next level, but at the same time, the missing answers will be taken into account at the next level. System will analyse where learner is making mistakes and find closely related topics which he or she has to study more. This system is an Ontology-driven system, because Ontology is a good instrument for presenting a knowledge base of learning process and relationships between different topics, as well as for creating a new knowledge. This system builds on the several surveyed systems and aims to utilize and enhance on their existing methods, such as internal analysis and personalized testing.

Particular solution allows personalizing learner's educational gaps due to the fact that incorrect answers will be taken into account in the next level. Accordingly, the student, who will take the whole course due to the rules, will be fully familiar with the material, which is proposed for the study. Also it will help on-the-fly in improving adult's knowledge in some particular domain. This technique also allows future maintaining of performance records according to various criteria, for example: to determine what topic is the most incomprehensible, also possible to draw conclusions about what is the relationship between age and the assimilation of the material, as well as any analytical conclusion is based on statistics, which in future will successfully affect the tuning (change) of the learning system.

\section{ACKNOWLEDGMENTS}

We would like to give our thanks to Aziz Hasanov for his invaluable help with the learning system survey during the writing of this paper.

\section{REFERENCES}

[1] Garrison, D. Randy. E-learning in the 21st century: A framework for research and practice. Taylor \& Francis, 2011.

[2] K. Mac Keogh and S. Fox, "Strategies for Embedding eLearning in Traditional Universities: Drivers and Barriers," vol. 7, no. 2, pp. 135-141, 2008.

[3] A. Latham, K. Crockett, D. McLean, and B. Edmonds, "A conversational intelligent tutoring system to automatically predict learning styles," Comput. Educ., vol. 59, no. 1, pp. 95-109, 2012. 
[4] G. J. Hwang, H. C. Chu, J. L. Shih, S. H. Huang, and C. C. Tsai, "A decision-tree-oriented guidance mechanism for conducting nature science observation activities in a context-aware ubiquitous learning environment," Educ. Technol. Soc., vol. 13, no. 2, pp. 53-64, 2010.

[5] C. R. Beal, "AnimalWatch: An Intelligent Tutoring System for Algebra Readiness," in International Handbook of Metacognition and Learning Technologies, vol. 28, no. January, R. Azevedo and V. Aleven, Eds. Springer, 2013, pp. 337-348.

[6] M. Siadaty et al., "Learn-B: A Social Analytics-enabled Tool for Self-regulated Workplace Learning," Proc. 2nd Int. Conf. Learn. Anal. Knowl. - LAK '12, p. 115, 2012.

[7] P.-H. Wu, G.-J. Hwang, L.-H. Su, and Y. Haung, "A Context-Aware Mobile Learning System for Supportive Cognitive Apprenticeships in Nursing Skills Training," Educ. Technol. Soc., vol. 5, no. 1, pp. 223-236, 2012.

[8] Ö. Özyurt, H. Özyurt, A. Baki, and B. Güven, "Integration into mathematics classrooms of an adaptive and intelligent individualized e-learning environment: Implementation and evaluation of UZWEBMAT," Comput. Human Behav., vol. 29, no. 3, pp. 726-738, 2013.

[9] I. H. Hsiao, S. Sosnovsky, and P. Brusilovsky, "Guiding students to the right questions: Adaptive navigation support in an E-Learning system for Java programming," J. Comput. Assist. Learn., vol. 26, no. 4, pp. 270-283, 2010.

[10] F. Bouchet, J. M. Harley, G. J. Trevors, and R. Azevedo, "Clustering and Profiling Students According to their Interactions with an Intelligent Tutoring System Fostering Self-Regulated Learning," JEDM - J. Educ. Data Min., vol. 5, no. 1, pp. 104-146, 2013.

[11] C. Limongelli, F. Sciarrone, M. Temperini, and G. Vaste, "The Lecomps5 framework for personalized web-based learning: A teacher's satisfaction perspective," Comput. Human Behav., vol. 27, no. 4, pp. 1310-1320, 2011.

[12] V. A. Nguyen, V. C. Pham, and S. D. Ho, "A Context-Aware Mobile Learning adaptive System for Supporting Foreigner Learning English," Comput. Commun. Technol. Res. Innov. Vis. Futur. (RIVF), 2010 IEEE RIVF Int. Conf., pp. 1-6, 2010.

[13] B. Zhang, C. Yin, B. David, Z. Xiong, and W. Niu, "Facilitating professionals' work-based learning with context-aware mobile system," Sci. Comput. Program., vol. 129, pp. 3-19, 2016.

[14] D. Gallego, E. Barra, S. Aguirre, and G. Huecas, "A model for generating proactive contextaware recommendations in e-Learning systems," in Proceedings - Frontiers in Education Conference, FIE, 2012.

[15] S. Gómez, P. Zervas, D. G. Sampson, and R. Fabregat, "Context-aware adaptive and personalized mobile learning delivery supported by UoLmP," J. King Saud Univ. - Comput. Inf. Sci., vol. 26, no. 1, pp. 47-61, 2014.

[16] B. Vesin, M. Ivanović, A. Klašnja-Milićević, and Z. Budimac, "Protus 2.0: Ontology-based semantic recommendation in programming tutoring system," Expert Syst. Appl., vol. 39, no. 15, pp. 12229-12246, 2012.

[17] I. Arroyo, B. P. Woolf, J. M. Royer, M. Tai, and S. English, "Improving math learning through intelligent tutoring and basic skills training," Lect. Notes Comput. Sci. (including Subser. Lect. Notes Artif. Intell. Lect. Notes Bioinformatics), vol. 6094 LNCS, no. PART 1, pp. 423-432, 2010.

[18] S. D'Mello, A. Olney, C. Williams, and P. Hays, "Gaze tutor: A gaze-reactive intelligent tutoring system," Int. J. Hum. Comput. Stud., vol. 70, no. 5, pp. 377-398, 2012.

[19] A. Harchay, L. Cheniti-Belcadhi, and R. Braham, "A Context-Aware Framework to Provide Personalized Mobile Assessment," Interact. Des. Archit., pp. 82-97, 2014.

[20] R. Z. Cabada, M. L. Barrón Estrada, and C. A. Reyes García, "EDUCA: A web 2.0 authoring tool for developing adaptive and intelligent tutoring systems using a Kohonen network," Expert Syst. Appl., vol. 38, no. 8, pp. 9522-9529, 2011.

[21] J. E. Gomez, J. F. Huete, and V. L. Hernandez, "A Contextualized System for Supporting Active Learning," IEEE Trans. Learn. Technol., vol. 9, no. 2, pp. 196-202, 2016.

[22] C.-C. Chen and P.-H. Lin, "Development and evaluation of a context-aware ubiquitous learning environment for astronomy education," Interact. Learn. Environ., vol. 24, no. 3, pp. 644-661, 
2016.

[23] M. Li, H. Ogata, B. Hou, N. Uosaki, and Y. Yano, "Personalization in context-aware ubiquitous learning-log system," Proc. 2012 17th IEEE Int. Conf. Wireless, Mob. Ubiquitous Technol. Educ. WMUTE 2012, pp. 41-48, 2012.

[24] R. Benlamri and X. Zhang, "Context-aware recommender for mobile learners," Human-centric Comput. Inf. Sci., vol. 4, no. 1, p. 12, 2014.

[25] Z. Sevarac, V. Devedzic, and J. Jovanovic, "Adaptive neuro-fuzzy pedagogical recommender," Expert Syst. Appl., vol. 39, no. 10, pp. 9797-9806, 2012.

[26] M. Vladoiu and Z. Constantinescu, "U-Learning within a Context-Aware Multiagent Environment," Int. J. Comput. Networks Commun., vol. 3, no. 1, pp. 1-15, 2011.

[27] E. Popescu, "Adaptation provisioning with respect to learning styles in a Web-based educational system: An experimental study," J. Comput. Assist. Learn., vol. 26, no. 4, pp. 243257, 2010.

[28] S. Alkhuraiji, B. Cheetham, and O. Bamasak, "Dynamic Adaptive Mechanism in Learning Management System Based on Learning Styles," 2011 IEEE 11th Int. Conf. Adv. Learn. Technol., pp. 215-217, 2011.

[29] N. Capuano, M. Gaeta, S. Salerno, and G. R. Mangione, "An Ontology-Based Approach for Context-Aware e-Learning," in 2011 Third International Conference on Intelligent Networking and Collaborative Systems, 2011, pp. 789-794.

[30] S. L. Wang and C. Y. Wu, "Application of context-aware and personalized recommendation to implement an adaptive ubiquitous learning system," Expert Syst. Appl., vol. 38, no. 9, pp. 10831-10838, 2011.

[31] M. Yaghmaie and A. Bahreininejad, "A context-aware adaptive learning system using agents," Expert Syst. Appl., vol. 38, no. 4, pp. 3280-3286, 2011.

[32] N. Kasaki, S. Kurabayashi, and Y. Kiyoki, "A geo-location context-aware mobile learning system with adaptive correlation computing methods," Procedia Comput. Sci., vol. 10, pp. 593600, 2012.

[33] H. O. Chorfi, A. Z. Sevkli, and F. Bousbahi, "Mobile learning adaption through a device based reasoning," Cyprus Int. Conf. Educ. Res., vol. 47, pp. 1707-1712, 2012.

[34] K. Scott and R. Benlamri, "Context-Aware Services for Smart Learning Spaces," vol. 3, no. 3, pp. 214-227, 2010.

[35] T.-C. Yang, G.-J. Hwang, and S. J.-H. Yang, "Development of an adaptive learning system with multiple perspectives based on students' learning styles and cognitive styles," Educ. Technol. Soc., vol. 16, no. 4, pp. 185-200, 2013.

[36] M. Yasir and S. Sharif, "An approach to Adaptive E-Learning Hypermedia System based on Learning Styles ( AEHS-LS ): Implementation and evaluation," Int. J. Libr. Inf. Sci., vol. 3, no. January, pp. 15-28, 2011.

[37] F. Akbari and F. Taghiyareh, "E-SoRS: A personalized and social recommender service for Elearning environments," in 8th National and 5th International Conference on e-Learning and eTeaching, ICeLET 2014, 2014, pp. 1-12.

[38] M. Salehi, I. Nakhai Kamalabadi, and M. B. Ghaznavi Ghoushchi, "An effective recommendation framework for personal learning environments using a learner preference tree and a GA," IEEE Trans. Learn. Technol., vol. 6, no. 4, pp. 350-363, 2013.

[39] "IBM Watson - Build Your Cognitive Business with IBM." .

[40] "Azure Cognitive Services Documentation - Tutorials, API Reference | Microsoft Docs." .

[41] L. Zhou, "Ontology learning: state of the art and open issues," Inf. Technol. Manag., vol. 8, no. 3, pp. 241-252, Aug. 2007.

[42] M. Gavriushenko, M. Kankaanranta, and P. Neittaanmaki, "Semantically enhanced decision support for learning management systems," in Semantic Computing (ICSC), 2015 IEEE International Conference on, 2015, pp. 298-305. 
[43] M. Gaeta, F. Orciuoli, and P. Ritrovato, "Advanced ontology management system for personalised e-Learning," Knowledge-Based Syst., vol. 22, no. 4, pp. 292-301, 2009.

[44] "Retrieve and Rank | Overview of the Retrieve and Rank service | IBM Watson Developer Cloud.". 